\title{
Dampak Pembangunan Jalur Jalan Lintas Selatan (JJLS) di Yogyakarta Terhadap Perubahan Penggunaan Lahan
}

\author{
Hendry Edy ${ }^{1)}$, Tantin Pristyawati ${ }^{2)}$ \\ 1) Fakultas Teknik, Program Studi Teknik Sipil, Universitas Gunung Kidul, Jl. KH Agus Salim, No.170, \\ Ledoksari, Kepek, Wonosari, Gunungkidul; Telp. 0274-391342. Email: hendry_edy@yahoo.com \\ 2) Fakultas Teknik, Program Studi Teknik Sipil, Universitas Veteran Bangun Nusantara, Sukoharjo, Jl. \\ Letjen Sudjono Humardhani, No.1, Jombor, Sukoharjo; Telp. 0271-593156. Email: \\ pristya_tan@yahoo.com
}

\begin{abstract}
Abstrak
Salah satu infrastruktur yang penting untuk menunjang kegiatan ekonomi adalah infrastruktur Jalan, seperti di daerah selatan Pulau Jawa dibangun JJLS oleh pemerintah sebagai salah satu upaya pemerintah melalui Kementrian Pekerjaan Umum untuk meningkatkan tersedianya infrastruktur yang bertujuan untuk mengurangi kepadatan transportasi di pantai Utara Jawa (Pantura) serta untuk memacu perkembangan wilayah di kawasan Selatan Jawa. Pembangunan tersebut tentu menimbulkan beberapa dampak, salah satunya adalah perubahan penggunaan lahan. Hal itulah yag digunakan sebagai dasar pada studi ini. Tujuannya untuk menganalisis perubahan tata guna lahan yang terjadi di Desa Jetis, dengan adanya pembangunan JJLS. Metode dalam penelitian ini merupakan metode kualitatif, dimana data awal penelitian ini diambil dengan menggunakan observasi langsung di lapangan dan juga wawancara dengan aparat desa dan masyarakat sekitar. Dengan model Miles and Huberman. Analisis dilakukan pada saat pengumpulan data berlangsung dan setelah selesai pengumpulan data pada periode waktu tertentu sampai diperoleh data yang kredibel dan sesuai dengan data yang dibutuhkan. Uji keabsahan data pada penelitian kualitatif meliputi uji, credibility (validitas internal), transferability (validitas eksternal), dependability (reliabilitas), dan confirmability (obyektivitas). Hasil penelitian yang dilakukan melalui pendekatan ana-lisis peta digital (sistem informasi geografis) dengan cara tumpang susun peta penggunaan lahan hasil interpretasi citra sebelum dan sesudah pembangunan JJLS, diperoleh bahwa belukar/ semak sebesar $1.68 \%$, sawah tadah hujan $1 \%$ dan tegalan mengalami pengurangan hampir 10,16\%. Sedangkan penambahan ter-jadi pada lahan pemukiman kurang lebih $13 \%$. Pola perubahan penggunaan lahan yang terjadi adalah pola tersebar. Perubahan penggunaan lahan yang terjadi dari lahan belukar, sawah tadah hujan dan tegalan menjadi pemukiman.
\end{abstract}

Kata kunci: JJLS, perubahan penggunaan lahan, Desa Jetis

\begin{abstract}
One of the important infrastructures to support economic activities is road infrastructure, such as in the southern area of Java Island JJLS was built by the government as one of the government's efforts through the Ministry of Public Works to increase the availability of infrastructure aimed at reducing transportation density on the north coast of Java (Pantura) and to spur regional development in the southern region of Java. The development certainly causes several impacts, one of which is land use change. This is what is used as the basis for this study. The aim is to analyze land use changes that occurred in Jetis Village, with the construction of JJLS. The method in this study is a qualitative method, where the initial data of this study were taken using direct observation in the field and also interviews with village officials and the surrounding community. With the Miles and Huberman model. The analysis was carried out at the time of data collection and after completion of data collection for a certain period of time until credible data was obtained and in accordance with the required data. The validity of the data in qualitative research includes tests, credibility (internal validity), transferability (external validity), dependability (reliability), and confirmability (objectivity). The results of research conducted through a digital map analysis approach (geographical information system) by overlapping land use maps resulting from image interpretation before and after the construction of JJLS, it was found that shrubs/shrubs were 1.68\%, rainfed rice fields were $1 \%$ and dry fields were dry. experienced a reduction of almost $10.16 \%$. While the addition occurred in residential land of approximately $13 \%$. The pattern of land use change that occurs is a scattered pattern. Changes in land use that occur from scrub land, rainfed rice fields and dry fields into settlements.
\end{abstract}

Keywords: JJLS, land use change, Jetis Desa Village

\section{PENDAHULUAN}

Pulau Jawa termasuk ke dalam kelompok kawasan berkembang di Indonesia, dimana tingkat perkembangan ekonominya pesat dan potensial. Hal ini dikarenakan pulau Jawa memiliki sumber daya alam dan sumber daya manusia (SDM) yang cukup besar. 
Daerah-daerah yang pembangunan dan pertumbuhan ekonominya baik pada umumnya berada di sepanjang pantai utara pulau Jawa seperti kota Semarang, Pati, Rembang dan Jepara. Sedangkan di bagian selatan pertumbuhan ekonominya cender-ung lebih lambat. Meskipun sebenarnya wlayah bagian selatan pulau Jawa memiliki potensi ekonomi yang besar antara lain tanah yang subur, sumber-sumber tambang, sumber daya laut, wisata pantai, wisata gua karst, wisata alam dan pegunungan, pariwisata hutan dan pariwisata budaya (peninggalan sejarah dan budaya tradisional). Potensi-potensi ini belum digarap dengan baik sehingga diperlukan pembangunan yang men-dukung pengembangan potensi, dimana pembangunan (development) juga dapat berarti mengadakan sesuatu atau membuat atau mengatur sesuatu yang belum ada, atau meningkatkan sesuatu yang sudah ada.(Jayadinata, 1999 : 4)

Pembangunan dalam hal ini lebih kepada pembangunan untuk tersedianya infrastruktur. Menurut (Joyo Winoto dan Hermanto Siregar, 2006). Ketersediaan infrastruktur dapat memberikan pengaruh pada peningkatan akses masyarakat terhadap sumberdaya sehingga meningkatkan akses produktivitas sumber daya yang pada akhirnya mendorong pertumbuhan ekonomi.

Salah satu infrastruktur yang pent-ing untuk menunjang kegiatan ekonomi adalah infrastruktur Jalan, seperti di dae-rah selatan Pulau Jawa dibangun JJLS oleh pemerintah sebagai salah satu upaya pemerintah melalui Kementrian Pekerjaan Umum untuk meningkatkan tersedianya infrastruktur yang bertujuan untuk mengurangi kepadatan transportasi di pantai Utara Jawa (Pantura) serta untuk memacu perkembangan wilayah di kawasan Selatan Jawa. Diantara beberapa wilayah yang dilewati JJLS, salah satunya adalah desa Jetis kecamatan Saptosari Kabupaten Gunungkidul DIY, yang mana tentu saja mengalami dampak dengan dibangunnya JJLS, seperti perubahan tata-guna lahan. Lahan adalah objek yang sangat penting karena merupakan input sekaligus produk dari proses perencanaan (Kaiser et al, 1995:196). Disebut input karena lahan merupakan modal dasar pembentukan ruang. Lahan merupakan wadah dari aktivitas yang memiliki nilai ekonomi yang penting dalam pembentukan permukiman yang dengan aktivitas yang kompleks. Beberapa perspektif yang harus diperhatikan dalam memahani penggunaan (landuse) :1.) Lahan adalah ruang fungsional yang diperuntukkan untuk mewadahi beragam penggunaan, 2.) Lahan adalah komoditas. Penggunaan lahan harus memperhatikan kemampuan fisik alamiah dan daya dukungnya.

Perubahan penggunaan lahan akan mungkin terjadi apabila adanya suatu kepentingan. Perubahan penggunaan lahan adalah kondisi terjadinya pertambahan suatu penggunaan lahan dari suatu penggunaan ke penggunaan yang lain dii-kuti dengan berkurangnya jenis penggunaan lahan yang lain dalam suatu waktu ke waktu selanjutnya, atau beru-bahnya fungsi suatu lahan pada waktu yang berbeda (Wahyunto dkk., 2001).

Berdasarkan kondisi tersebut, studi ini bertujuan untuk menganalis perubahan tata guna lahan di sekitar wilayah pembangunan JJLS. Sebagai pendukung penelitian ini menurut (Valentine, 2012), harapan dari para stakeholder terhadap implementasi pembangunan JJLS Kabupaten Gunungkidul yaitu mengembangkan pembangunan agar tidak tertinggal dengan wilayah lain, infrastruktur jalan lebih memadai, terbukanya kantong kantong ekonomi, peningkatan pendapatan masyarakat lokal, pembangunan perlu pengawasan dan pengendalian ketat, interaksi positif para stakeholder, tanah kas desa mendapat ganti rugi, pemberlakuan insentif dan disinsentif baik di masyarakat lokal, lembaga swasta maupun pemerintah daerah. (Marsista, 2015), pembangunan Jalan Lingkar Selatan Salatiga belum berpengaruh secara signifikan terhadap perubahan karakteristik sosial ekonomi penduduk di sekitarnya. Perubahan tersebut belum secara merata terjadi di sepanjang Jalan Lingkar Selatan Salatiga karena perkembangan masih terjadi secara sporadis dalam artian perkembangan terjadi secara tidak merata dan hanya terjadi di beberapa lokasi di sekitar Jalan Lingkar Selatan Salatiga. Sedangkan menurut (Eko T, 2012) Studi ini menganalisis foto udara dan gambar satelit melalui proses overlay dan analisis Inputoutput, disertai analisis SWOT atas kebijakan kebijakan guna lahan. Hasil menunjukkan bahwa $10,32 \%$ guna lahan di Mlati berubah sepanjang kurun waktu 1996 - 2010, yang mengakibatkan hilangnya 290,67 acre area pertanian dengan $13,12 \%$ diantaranya berubah men-jadi permukiman. Namun demikian, 
$65,9 \%$ dari guna lahan disana masih sesuai dengan dokumen perencanaan. Wilayah ini kekurangan aspek hukum dalam pen-erapan kebijakan tata guna lahannya ka-rena dokumen perencanaan belum disahkan.

\section{METODE}

Metode dalam penelitian ini meru-pakan metode kualitatif, dimana menurut Satori (2010) bahwa penelitian kualitatif adalah penelitian yang menekankan pada quality atau hal yang terpenting dari sifat suatu barang atau jasa. Hal yang ter-penting dari suatu barang atau jasa berupa kejadian/ fenomena/ gejala sosial adalah makna dibalik kejadian tersebut yang dapat dijadikan pelajaran berharga bagi suatu pengembangan konsep teori. Data awal penelitian ini diambil dengan menggunakan observasi langsung di lapangan dan juga wawancara dengan apa-rat desa dan masyarakat sekitar. Penelitian ini bersifat penelitian penjelasan (ex-planatory research) karena penelitian ini mencoba menjelaskan bagaimana dampak pembangunan JJLS terhadap kehidupan masyarakat sekitar.

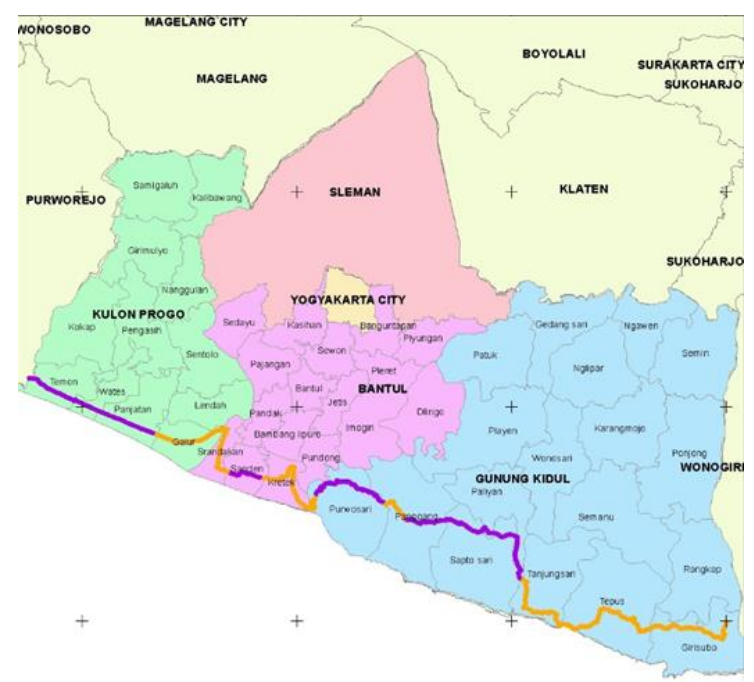

Gambar 1. Peta Jaringan Jalan Lintas Selatan di Daerah Istimewa Yogyakarta

Pengumpulan data-data yang diperlukan dalam penelitian dibagi menjadi dua yaitu data primer dan data sekunder. Data primer dikumpulkan melaui indepth interview penulis kepada informan yang mengalami proses pembangunan JJLS dari awal hingga akhir pembangunan. Sedangkan data sekunder diperoleh dari instansi terkait, seperti Badan Pusat Statistik, Dinas Pekerjaan Umum, Perumahan dan Sumber Daya Mineral, Provinsi Daerah
Istimewa Yogyakarta. Setelah data-data terkumpul, dilakukan reduksi data dengan merangkum, memilih hal-hal pokok, fokus terhadap masalah yang akan diteliti. Langkah selanjutnya adalah melakukan display data, kemudian penarikan kesimpulan dan verifikasi. Kesimpulan awal yang dikemukakan masih bersifat sementara, dan akan berubah bila tidak ditemukan bukti-bukti kuat yang mendukung pada tahap pengumpulan data berikutnya.

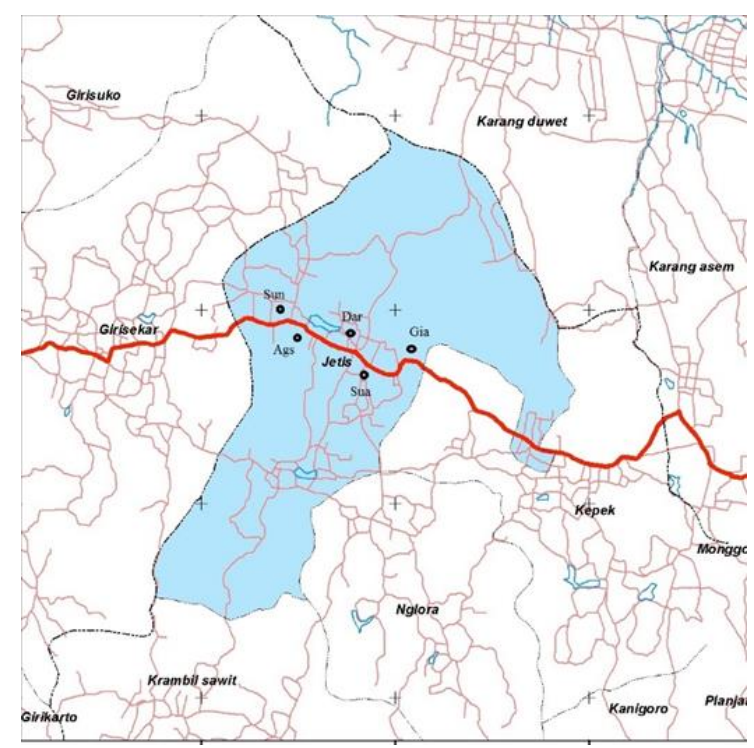

Gambar 2. Peta Administrasi Desa Jetis Kecamatan Saptosari, Kabupaten Gunungkidul

Penelitian ini analisis data dilakukan dengan model Miles and Huberman. Analisis dilakukan pada saat pengumpulan data berlangsung dan setelah selesai pengumpulan data pada periode waktu tertentu. Pada saat melakukan wawancara, sudah dilakukan analisis terhadap jawaban dari yang diwawancarai. Jika setelah dianalisis jawaban dari yang diwawancarai belum memuaskan, maka pertanyaannya akan dilanjutkan lagi sampai diperoleh data yang kredibel dan sesuai dengan data yang dibutuhkan.

Uji keabsahan data pada penelitian kualitatif meliputi uji, credibility (validitas internal), transferability (validitas eksternal), dependability (reliabilitas), dan confirmability (obyektivitas).

\section{HASIL DAN PEMBAHASAN}

Desa Jetis terletak di kecamatan saptosari Kabupaten Gunungkidul. Luas Desa Jetis 843,895 Ha dengan batas wilayah sebelah Utara adalah desa Krangduwet, kecamatan Paliyan, sebelah selatan Desa Ngloro, kecamatan 
Saptosari, sebelah timur desa Kepek, kecamatan Saptosari dan sebelah barat desa Girisekar, kecamatan Panggang.

Pembangunan Jalur Jalan Lintas Selatan di desa Jetis ini dimulai dengan pembebasan tanah yang akan digunakan untuk pelebaran jalan yang sudah ada pada tahun 2014 sampai 2015. Kemudian pada tahun 2016 dilakukan pembangunan JJLS dan selesai pada tahun 2016. Lebar JJLS di Desa Jetis ini $7 \mathrm{~m}$ dan panjang jalan yang melewati desa ini sekitar 7 $\mathrm{km}$.

Perubahan lahan di desa Jetis kecamatan Saptosari, Kabupaten Gunung Kidul diketahui dengan cara pendekatan analisis peta digital. Analisis peta digital dengan menggunakan sistem informasi geografis yang dilakukan dengan cara tumpang susun peta penggunaan lahan hasil interpretasi citra tahun 2013 saat pembangunan JJLS belum dilaksanakan dan tahun 2017 saat pembangunan JJLS telah selesai dilaksanakan.

Pada tahun 2013 penggunaan lahan di desa Jetis ditunjukkan pada Gambar 3.

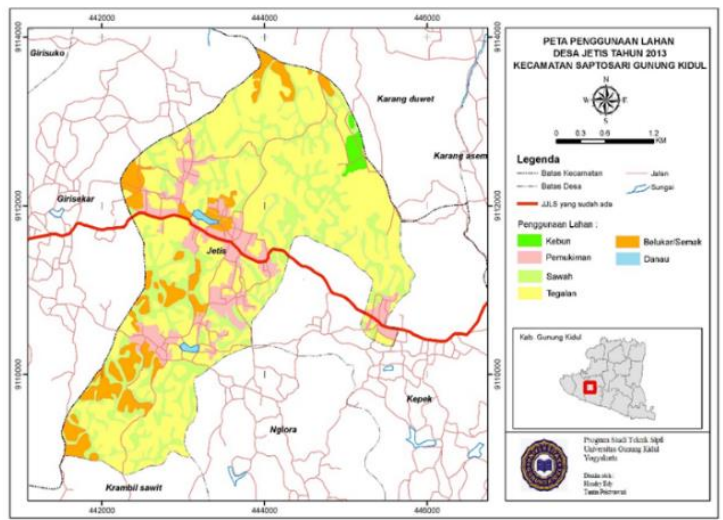

Gambar 3. Penggunaan lahan di desa Jetis

Sedangkan untuk masing - masing penggunaan lahan ditunjukkan pada Tabel 1. Dimana penggunaan lahan sebagai tegalan lebih dari $50 \%$ dari total keseluruhan penggunaan lahan, artinya bahwa tegalan mendominasi penggunaan lahan. Dan selanjutnya yang kedua adalah sawah tadah hujan dengan luas kurang lebih $200 \mathrm{Ha}$. Penggunaan lahan yang lain adalah belukar/semak, permkiman, kebun dan danau.

Pada tahun 2017 setelah pembangunan JJLS selesai dilaksanakan, terjadi perubahan penggunaan lahan seperti ditunjukkan pada Gambar 4.
Tabel 1. Luas Penggunaan Lahan Desa Jetis Tahun 2013

\begin{tabular}{llrr}
\hline No & $\begin{array}{l}\text { Penggunaan } \\
\text { Lahan }\end{array}$ & \multicolumn{1}{c}{$\begin{array}{c}\text { Luas } \\
\text { (Ha) }\end{array}$} & \multicolumn{1}{c}{$\begin{array}{c}\text { Persentase } \\
\text { Luas (\%) }\end{array}$} \\
\hline 1 & Danau & 3,73 & 0,38 \\
2 & Belukar/Semak & 106.17 & 10,76 \\
3 & Kebun & 11,03 & 1,12 \\
4 & Pemukiman & 103,42 & 10,48 \\
5 & Sawah Tadah & 216,24 & 21,92 \\
& Hujan & & \\
6 & Tegalan & 545,83 & 55,33 \\
\hline
\end{tabular}

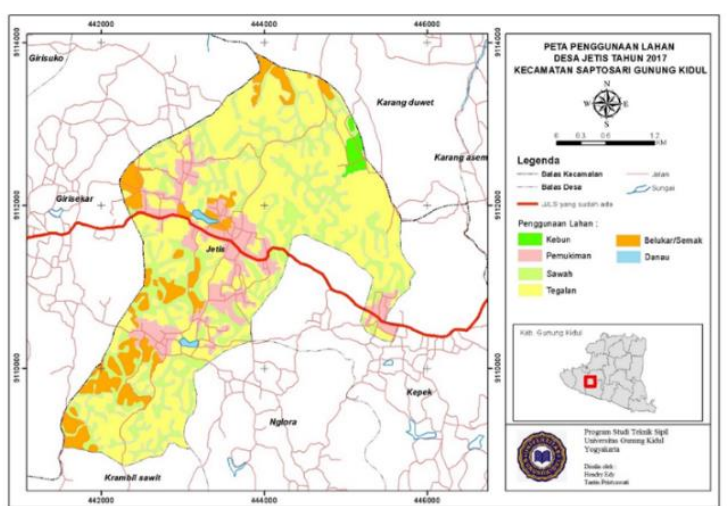

Gambar 4. Perubahan penggunaan lahan setelah pembangunan JJLS selesai dilaksanakan

Luas untuk masing-masing penggunaan lahan ditunjukkan pada Tabel 2.

Tabel 2. Luas Penggunaan Lahan Desa Jetis Tahun 2017

\begin{tabular}{llrr}
\hline No & $\begin{array}{l}\text { Penggunaan } \\
\text { Lahan }\end{array}$ & \multicolumn{1}{c}{$\begin{array}{l}\text { Luas } \\
\text { (Ha) }\end{array}$} & \multicolumn{1}{c}{$\begin{array}{l}\text { Persentase } \\
\text { Luas (\%) }\end{array}$} \\
\hline 1 & Danau & 3,73 & 0,38 \\
2 & Belukar/Semak & 104.49 & 10,59 \\
3 & Kebun & 11,03 & 1,12 \\
4 & Pemukiman & 116,26 & 11,79 \\
5 & Sawah Tadah & 215,24 & 21,82 \\
& Hujan & & \\
6 & Tegalan & 535,67 & 54,30 \\
\hline
\end{tabular}

Perubahan lahan di Desa Jetis Kecamatan Saptosari, Kabupaten Gunungkidul diketahui dengan cara pendekatan analisis peta digital. Analisis peta digital dengan menggunakan sistem informasi geografis yang dilakukan dengan cara tumpang susun peta penggunaan lahan hasil interpretasi citra tahun 2013 saat pembangunan JJLS belum dilaksanakan dan tahun 2017 saat pembangunan JJLS telah selesai dilaksanakan. 


\section{SIMPULAN}

Hasil dari analisis menunjukkan bahwa dampak dari pembangunan JJLS di desa Jetis Kecamatan Saptosari Kabupaten Gunungkidul, berdasarkan pendekatan analisis peta digital diperoleh bahwa luas penggunaan lahan ada pengurangan dan penambahan. Pengurangan terjadi pada luas belukar/ semak sebesar $1.68 \%$, sawah tadah hujan $1 \%$ dan tegalan mengalami pengurangan hampir $10,16 \%$. Sedangkan penambahan terjadi pada lahan pemukiman kurang lebih $13 \%$. Pola perubahan penggunaan lahan yang terjadi adalah pola tersebar. Perubahan penggunaan lahan yang terjadi dari lahan belukar, sawah tadah hujan dan tegalan menjadi pemukiman.

\section{DAFTAR PUSTAKA}

Eko, T. dan Rahayu, S., 2012, "Perubahan Penggunaan Lahan dan Kesesuaiannya terhadap RDTR di Wilayah Peri-Urban Studi Kasus: Kecamatan Mlati”, Jurnal Pembangunan Wilayah \& Kota, ISSN: 18583903, Vol: 8, Issue: 4, Page: 330-340

Jayadinata, Johara T., 1999. Tata Guna Lahan Dalam Perencanaan Pedesaan Perkotaan dan Wilayah. ITB Bandung, Bandung
Kaiser, J.,E., Godschalk, D., R., Chafin, S., F., 1995, Urban land use planning. Fourth edition. University of Illinois Press.

Marsista Buana Putri, 2015, Pengaruh Pembangunan Jalan Lingkar Selatan Salatiga terhadap Perubahan Karakteristik sosial Ekonomi Penduduk di Sekitarnya. Jurnal Pembangunan Wilayah dan Kota, Vol 11 (2), hal 222-241, Undip, Semarang

Satori Djamán, 2010, Metodologi Penelitian Kualitatif, Alfabeta, Bandung.

Valentine Kirana Herhayuningtyas, R. Rijanta, 2012, Persepsi Stakeholder Terhadap Implementasi Pembangunan Jalur Jalan Lintas Selatan Kabupeten Gunungkidul, Jurnal Bumi Indonesia, Volume 1 Nomor 2, UGM, Yogyakarta

Winoto J. dan Siregar H., 2006, Peranan Pembangunan Infrastruktur Dalam Menggerakkan Sektor Riil. Jurnal Ekonomi Indoenesia. No.1 Juni 2006, Jakarta

Wahyunto, M.Z. Abidin, A. Priyono, dan Sunaryo. "Studi Perubahan Lahan di Sub DAS Citarik, Jawa Barat dan DAS Kaligarang Jawa Tengah.” Prosiding Seminar Nasional Multifungsi Lahan Sawah. Hal 39-40. Bogor 1 Mei 2001. 